\title{
Outcome of obstetric cases with acute severe illness admitted to intensive care unit in a tertiary referral hospital in south India
}

\author{
Shivamurthy $\mathrm{H} \mathrm{M}^{1 *}$, Ashalata Mallapur ${ }^{2}$, Natasha $\mathrm{H} \mathrm{K}^{3}$, Santhosh Rathod ${ }^{3}$, Sneha Bhumakar ${ }^{4}$, \\ Ayesha ${ }^{4}$, Aishwarya Rajendra ${ }^{5}$, S B Kale ${ }^{5}$
}

${ }^{1}$ Professoer \& Unit Head, ${ }^{2}$ Professor \& HOD, ${ }^{3}$ Assistant Professor, ${ }^{4}$ Post Graduate Cum Resident, ${ }^{5}$ Head of MRO, Department of Obstetrics and Gynaecology, S N Medical College, Bagalkot, Karnataka, INDIA.

Email: dr shivamurthy2003@yahoo.com

Abstract Background: To analyse the demographic, clinical parameters and outcome of patients with severe acute maternal illness, admitted Intensive care unit in a Tertiary referral Hospital in South India Design: Two-year retrospective analytical study. Setting: HSK Hospital attached to S N Medical college, Bagalkot, Karnataka, South India. Methods: where as A 'nearmiss' describes a patient with an acute organ system dysfunction, which if not treated appropriately, could result in death. And SAMM cases are those in which women suffered from life threatening complications and who survived by good fortune and good hospital care. We took the term "acute severe maternal illness" as we came across maternal death also The case records of women satisfying this criteria were analysed and computed. Outcome measure: to determine the patient demography, clinical features, management protocols and outcome. Results: We had 27 cases acute severe maternal illness and 2 maternal deaths during our study. The reason for acute severe maternal ill ness were: Rupture uterus leading to shock (18\%), PPH (18\%), Eclampsia (7.4\%) Rupture of ectopic pregnancy (14.8\%)

Key words: Acute Severe Maternal Illness, SAMM, Near Miss Cases, Maternal Morbidity, Intesive Matrenal care Unit,

*Address for Correspondence:

Dr Shivamurthy H M, Professoer And Unit Head, Department of Obstetrics and Gynaecology, S N Medical College, Bagalkot, Karnataka, INDIA.

Email: dr_shivamurthy2003@yahoo.com

Received Date: 03/04/2020 Revised Date: 12/05/2020 Accepted Date: 20/07/2020

DOI: https://doi.org/10.26611/10121535

This work is licensed under a Creative Commons Attribution-NonCommercial 4.0 International License.

\begin{tabular}{|l|l|}
\hline \multicolumn{2}{|c|}{ Access this article online } \\
\hline Quick Response Code: & Website: \\
& www.medpulse.in \\
& \\
\hline
\end{tabular}

\section{INTRODUCTION}

Though High risk obstetric cases are frequently admitted to high dependency (intensive care) units, how ever any case may turn out to be risky in the course of labour and post partum. Though the terms SAMM (severe acute maternal morbidity) and "Near miss" cases are used almost with same intention but they need to be defined.

SAMM: definition Severe acute maternal morbidity (SAMM) cases are those in which women suffered from life threatening complications and who survived by good fortune and good hospital care. ${ }^{1}$

Where as Maternal near miss case is defined as "a woman who nearly died but survived a complication that occurred during pregnancy, childbirth, or within 42 days of termination of pregnancy" 2 About $8 \%$ of the global burden of the disease in women of reproductive age group is attributed to pregnancy and childbirth related conditions in South-east Asian and African countries ${ }^{3}$ Between 0.1 to $0.9 \%$ women develop complication of pregnancy require ICU admission About 0.43 of all ICU admissions are from obstetric field, of $0.24 \%$ were deliveries ${ }^{1}$ The frequency of severe postpartum maternal morbidity requiring tertiary hospital care was $4 \% .{ }^{1}$ Severe acute maternal morbidity 
identified as much as five times as many cases as maternal death ${ }^{4}$ The stepwise progression of maternal condition to severe acute morbidity is explained by Gerald $\mathrm{D}$ et al. in a progressive pyramid

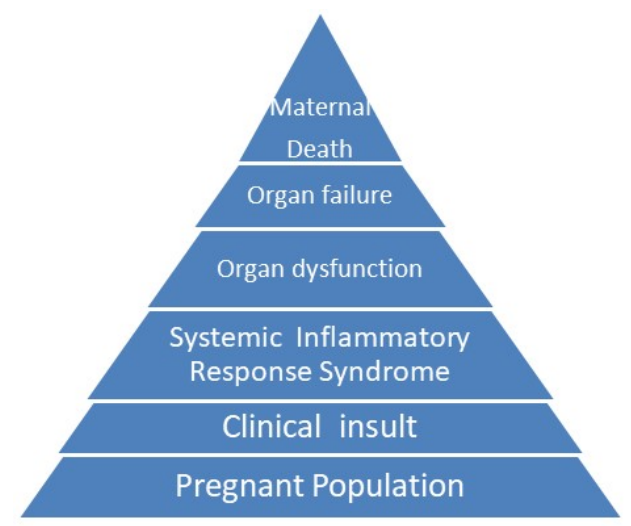

Figurr 1: Diagrammatic sequence of events from a normal healthy pregnancy to death in a pregnant population. ${ }^{4}$

Causes underlying these "near miss " cases were PPH , Preeclampsia, sepsis and anemia were important in a study by Seema bibi et al. ${ }^{1}$ Lack of proper antenatal care and delay in ICU referral are easily preventable factors that affect outcome 5 The patients demographic factors can operate at three levels leading to delay in getting appropriate treatment. ${ }^{6}$

- Delay in deciding to seek care (phase 1 delay).

- Delay in identifying and reaching care (phase 2 delay).

- Delay in receiving appropriate care in hospital (phase 3 delay).

Supporting mothers during pregnancy, labour and puerperium will not only save mothers but likely will slash deaths of newborns. ${ }^{7}$ Considerable morbidity is seen in these patients. In their study by Freda Richa et al. The maternal mortality in pts admitted to obstetric ICU was $33.3 \%{ }^{8}$ Continuous psychosocial follow up of those survived is necessary as their longterm health-related quality of life is impaired. ${ }^{9}$ Considering these factors, we took this study was undertaken to note the patients demographic factors, underlying obstetric condition , indications for admission to ICU and outcome .

\section{MATERIALS AND METHODS}

This retrospective study of 2 year done from May 2018 to May 2020, was based on all obstetric patients data, admitted to the Intensive Care Unit at HSK Hospital attached to S N Medical college, Bagalkot, Karnataka in south India, which is a tertiary referral Hospital. Data collected included Maternal age, Literacy, Socio economic status, Gestational age, Parity, any Medical comorbidities in the present pregnancy medical and obstetric history. Delivery data included type of delivery and any complications during delivery or post partum. We documented Indication for ICU transfer, antibiotics used, duration of ICU stay and outcome including maternal death (cause of death in case of death)

\section{RESULTS}

The results are depicted in the following tables

\begin{tabular}{cccc}
\multicolumn{4}{c}{ Table 1: Showing age distribution of patients } \\
\hline SI no & Age in years & Nos & $\%$ \\
\hline 1 & Up to 20 & 3 & 11.1 \\
2 & $20-25$ & 10 & 37.0 \\
3 & $25-30$ & 12 & 44.4 \\
3 & More than 30 & 2 & 7.4 \\
\hline
\end{tabular}

Table 2: showing Education Status

\begin{tabular}{cccc}
\hline & Education & Nos & $\%$ \\
\hline 1 & Illiterate & 4 & 14.8 \\
2 & Up to $7^{\text {th }}$ std & 8 & 29.6 \\
3 & $7^{\text {th }}-10^{\text {th }}$ std & 7 & 25.9 \\
4 & $10^{\text {th }}$ to $12^{\text {th }}$ & 5 & 18.5 \\
5 & Graduate & 3 & 11.1 \\
\hline
\end{tabular}

Table 3: Socio economic status

\begin{tabular}{cccc}
\hline SI no & Socio economic class & Nos & $\%$ \\
\hline 1 & Class I & 4 & 14.81 \\
2 & II & 8 & 29.62 \\
3 & III & 12 & 44.4 \\
4 & IV & 3 & 11.1 \\
\hline
\end{tabular}

\begin{tabular}{cccc}
\multicolumn{5}{c}{ Table 4: showing gravidity } \\
\hline SI no & Age in years & Nos & $\%$ \\
\hline 1 & 1 & 10 & 37 \\
2 & 2 & 9 & 33.3 \\
3 & 3 & 2 & 7.4 \\
3 & 4 & 4 & 14.8 \\
5 & 5 & - & \\
6 & 6 & 2 & 7.4 \\
\hline
\end{tabular}

\begin{tabular}{cccc}
\multicolumn{4}{c}{ Table 5: showing parity } \\
\hline SI no & Para & Nos & $\%$ \\
\hline 1 & 0 & 1 & 3.7 \\
2 & 1 & 11 & 40.74 \\
3 & 2 & 8 & 29.62 \\
4 & 3 & 3 & 11.1 \\
5 & 4 & 2 & 7.4 \\
6 & 5 & 2 & 7.4
\end{tabular}

Table 6: showing diagnosis

\begin{tabular}{cccc}
\hline SI No & Diagnosis & No & $\%$ \\
\hline 1 & Rupture uterus & 5 & 18.5 \\
2 & Ruptured ectopic pregnancy & 4 & 14.8 \\
3 & Traumatic pph & 3 & 11.1 \\
4 & Atonic PPH & 2 & 7.4 \\
\hline
\end{tabular}




\begin{tabular}{cccc}
\hline 5 & HELLP syndrome & 2 & 7.4 \\
6 & Post partum eclampsia & 2 & 7.4 \\
7 & Cardiac disease & 2 & 7.4 \\
8 & Severe anaemia with & 1 & 3.7 \\
& thrombocytopenia & & \\
9 & Multiple pregnancy with PPH & 1 & 3.7 \\
10 & Secondary PPH & 1 & 3.7 \\
11 & Uterine scar rupture & 1 & 3.7 \\
12 & Third degree perineal tearwith PPH & 1 & 3.7 \\
13 & Chorioamnionitis with septic shock & 1 & 3.7 \\
14 & Small bowel abstruction with sepsis & 1 & 3.7 \\
15 & Severe Respiratory infection & 1 & 3.7 \\
& ( pneumonia) & & \\
\hline
\end{tabular}

\begin{tabular}{|c|c|c|c|}
\hline SI no & Indication & Nos & $\%$ \\
\hline 1 & Hypovolemic shock & 19 & 70.3 \\
\hline 2 & Septic shock & 3 & 11.1 \\
\hline 3 & HELLP syndrome & 2 & 7.4 \\
\hline 4 & $\begin{array}{l}\text { Severe anaemia with } \\
\text { thrombocytopenia }\end{array}$ & 1 & 3.7 \\
\hline 5 & Rhd with CCF & 1 & 3.7 \\
\hline \multicolumn{4}{|c|}{ Table 8: showing antibiotics used } \\
\hline no & Antibiotics used in ICU & No & $\%$ \\
\hline 1 & Piperacillin with Metranidazole & 14 & 51.85 \\
\hline 2 & $\begin{array}{c}\text { Amoxycillin with Clavulanic acid and } \\
\text { Metranidazole }\end{array}$ & 9 & 33.3 \\
\hline 3 & Cefotaxime and Metranidazole & 2 & 7.4 \\
\hline 4 & Cefotaxime and Ornidazole & 1 & 3.7 \\
\hline 5 & Meropenam & 1 & 3.7 \\
\hline \multicolumn{4}{|c|}{ Table 9: procedure done in ICU } \\
\hline SI no & Procedure done & W & no \\
\hline 1 & Laparotomy for ruptured ute & & 2 \\
\hline 2 & Laparotomy for ectopic pregn & ncy & 1 \\
\hline 3 & $\begin{array}{l}\text { Laparotomy followed by end to end s } \\
\text { anastomosis }\end{array}$ & nall bowel & 1 \\
\hline
\end{tabular}

\begin{tabular}{cccc}
\multicolumn{5}{c}{ Table 10: showing no of days of stay in ICU } \\
\hline SI no & No of days of stay in ICU & Nos & $\%$ \\
\hline 1 & $1-3$ days & 8 & 29.6 \\
2 & $4-6$ days & 14 & $51.85 \%$ \\
3 & $7-10$ days & 4 & $14.81 \%$ \\
4 & $>10$ days & 1 & $3.7 \%$ \\
\hline
\end{tabular}

Table 11: showing outcome of admission to ICU

\begin{tabular}{ccc}
\hline Slno & Outcome & no \\
\hline 1 & Recovered & 25 \\
2 & Deaths & 2 \\
\hline
\end{tabular}

Table 12: showing cause of maternal death

\begin{tabular}{ccc}
\hline SI no & Cause of Maternal death & no \\
\hline 1 & Severe sepsis in a case of acute small bowel & 1 \\
obstruction & $\begin{array}{c}\text { Septic shock with septic abortion } \\
2\end{array}$ & 1 \\
\hline
\end{tabular}

\section{DISCUSSION}

We had total of 27 admissions to ICU out of 6752 obtetric admissions in 2 years giving an incidence of $0.39 \%$. This is in accordance with study by Fredrich et al. In our study, majority (44.4\%) patients were in the age group 25 to 30 years. also we had 3 patients below 20 years, which shows teen age marriage is still practiced in our location which needs to be discouraged for better obstetric outcomes. The most common age-groups of 21-25 years shows that comparatively younger age groups are involved. ${ }^{10}$ Eight $(29.6 \%)$ were educated up to $7^{\text {th }}$ std only and only 3 were graduates. This insists on women education which has bearing on matherhood. Interestingly $12(44.4 \%)$ were in the socio economic class 3 , which reflects better to do status which supports these expectant mothers nutritional status as only 3 mothers had anaemia. There were $10(37 \%)$ primigravida in our study which warns us that maternal severe acute illness was common in primigaraviae and calls for due care. So also 11(40.7\%) were Para1, showing patients in their early parahood are at risk of developing acute maternal illness. The obsteric pathology, which led to acute maternal illness, 5(18.5\%) cases had Ruptured uterus, $4 \quad(14.5 \%)$ had ruptured Ectopic pregnancy, $5(18.5 \%)$ had Post partum Haemarrhages, 2 had HELLP Syndrome and 2 had Eclampsia.

Compare and comment.

There were 4 medical co-morbidities, 2 cardiac, 1 diabetes mellitus and 1 Respiratory severe infection. Presence of comorbidities will affect the maternal outcome drastically. Compare and comment.

We had 19 (70.3\%) cases had hypovolemic shock, followed by 3cases septic shock, which underlines the proper management of obstetric conditions which result in these two important maternal killers.

Compare and comment

Our patients were given Piperacillin $4.5 \mathrm{Gms}$ twice a day and Metronidazole $500 \mathrm{mg} 8^{\text {th }}$ hourly both by i v route in $14(51.8 \%)$ of cases with excellent results. The other common combination was Amoxycillin $1 \mathrm{gm}$ twice a day by iv and Metranidazole in 9 (33.3\%). In one case there was need to switchover of antibiotic from Amoxycillin plus Clavulanic acid to Meropenam but unfortunately this patient succumbed due to severe sepsis. We had 14 $(51.8 \%)$ patients who stayed in ICU for 4-6 days. How ever $8(29.6 \%)$ cases stayed only for 3 days in ICU. This is in accordance with the study by Freda Richa et al. where the mean duration of ICU stay was $7 \pm 5$ days $^{5}$ There were two laparotomies done during ICU admissions. One for ruptured ectopic pregnancy and one where intestinal end to end anastomosis was done. These two patients were shifted to ICU directly on admission itself, as there condition was critical at demission only. Usually obstetric patients will be shifted to ICU after managing the case in obstetric arena. 
There were two maternal deaths in ICU inspite all possible measures giving an incidence of $7.4 \%$. We had 2 maternal deaths out of 27 , giving an incidence of $7.4 \%$. There was $33.3 \%$ of maternal mortality as per the study by J Med Liban et al. This depends on the underlying pathology, associated maternal comorbidities and the level of multispeciality medical care available in ICU. This way our ICU care was reasonably good.

Limitation for this study

This study include cases for only 2 years and had 27 cases and these observations may not apply for larger population and calls for study in a larger population.

\section{CONCLUSION}

There is a need for maternal intensive care in all Obstetrics practicing setps where these patients freup in severe catastrophy .Early admission and management of critically ill obstetric patients in the ICU may decrease maternal mortality and morbidity.

\section{REFERENCES}

1. Seema Bibi, FCPS, Saima Ghaffar FCPS, Shazia Memon FCPS, Shaneela Memon FCPS. Original Article Severe acute maternal morbidity (SAMM) in postpartum period requiring tertiary Hospital care Iran J Reprod Med Vol. 10. No. 2. pp: 87-92, March 2012

2. Say L, Souza JP, Pattinson RC. Maternal near misstowards a standard tool for monitoring quality of maternal health care. Best Practice and Research. 2009;23(3):287296.

3. The Global Burden of Disease 2004 Update. World Health Organization. Geneva; Switzerland; 2008\}.

4. Gerald D. Mantel, Eckhart Buchmann, Helen Rees, Robert C. Pattinson BJOG - Volume 105, Issue 9 September 1998 Pages 985-990, Severe acute maternal morbidity: a pilot study of a definition for a near-miss 19 AUG 2005

5. 5 Karnad DR, Lapsia V, Krishnan A, Salvi S. Prognostic factors in obstetric patients admitted to an Indian intensive care unit. Critical Care Medicine. 2004;32(6):1294-9

6. 6 Akker T, Rhenen JV, Mwagomba B, Lommerse K, Vinkhumbo S, Roosmalen JV. Reduction of severe acute maternal morbidity and maternal mortality in thyolo district, malawi: the impact of obstetric audit. PLoS One. 2011;6(6):e20776.

7. Souza JP, Cecatti JG, Faundes A, Morais SS, Villar J, Carroli GB, et al.. Maternal near miss and maternal death in the World Health Organization's 2005 global survey on maternal and perinatal health. Bull World Health Organ 2010; 88: 113-119.

8. Freda Richa ${ }^{1}$, Nabil Karim, Patricia Yazbeck Comparative Study J Med Liban . Oct- Dec 2008;56(4):215-9.Obstetric Admissions to the Intensive Care Unit: An Eight-Year Review 2008.

9. Leung NY, Lau AC, Chan KK, Yan WW. Clinical characteristics and Outcomes of obstetric patients admitted to the intensive care unit: a 10-year retrospective review. Hong Kong Med J. 2010;16(1):18-25.

10. Bibi S, Memon A, Sheikh JM, Qureshi AH. Severe acute maternal morbidity and intensive care in a public sector university hospital of Pakistan. J Ayub Med Coll Abbottabad. 2008;20(1):109-12.

Source of Support: None Declared Conflict of Interest: None Declared 